\title{
Synthesis of Nitrogen-Doped ZnS with Camellia Brushfield Yellow Nanostructures for Enhanced Photocatalytic Activity under Visible Light Irradiation
}

\author{
Gang-Juan Lee, ${ }^{1}$ Chi-Lun Hong, ${ }^{1}$ Valentina Batalova, ${ }^{2}$ \\ Gennady Mokrousov, ${ }^{2}$ and Jerry $\mathrm{Wu}^{1}$ \\ ${ }^{1}$ Department of Environmental Engineering and Science, Feng Chia University, Taichung 407, Taiwan
}

${ }^{2}$ Department of Chemistry, Tomsk State University, Tomsk 634050, Russia

Correspondence should be addressed to Jerry Wu; jjwu@fcu.edu.tw

Received 31 May 2013; Revised 1 August 2013; Accepted 18 August 2013

Academic Editor: Manickavachagam Muruganandham

Copyright (c) 2013 Gang-Juan Lee et al. This is an open access article distributed under the Creative Commons Attribution License, which permits unrestricted use, distribution, and reproduction in any medium, provided the original work is properly cited.

Nitrogen modified zinc sulfide photocatalysts were successfully prepared and characterized by X-ray diffraction (XRD), field emission scanning electron microscopy (FE-SEM), high-resolution transmission electron microscopy (HR-TEM), X-ray photoelectron spectroscopy (XPS), and surface area analysis. Thermal decomposition of the semisolid was carried out under nitrogen conditions at $500^{\circ} \mathrm{C}$ for 2 hours, and a series of nitrogen-doped $\mathrm{ZnS}$ photocatalysts were produced by controlling inflow flow rate of nitrogen at $15-140 \mathrm{~mL} / \mathrm{min}$. Optical characterizations of the synthesized N-doping ZnS substantially show the shifted photoabsorption properties from ultraviolet (UV) region to visible light. The band gaps of nitrogen-doped ZnS composite catalysts were calculated to be in the range of $2.58 \sim 2.74 \mathrm{eV}$ from the absorptions edge position. The $15 \mathrm{~N} / \mathrm{ZnS}$ catalyst shows the highest photocatalytic activity, which results in $75.7 \%$ degradation of Orange II dye in 5 hrs by visible light irradiation, compared with pristine $\mathrm{ZnS}$ and higher percentage $\mathrm{N}$-doping $\mathrm{ZnS}$ photocatalysts.

\section{Introduction}

The photocatalytic degradation of organic pollutions present in water and wastewater has been comprehensively investigated with the use of photocatalysts and a solar light simulating source [1]. Since zinc sulfide ( $\mathrm{ZnS})$ is an important II-VI semiconductor with a large band gap, it has been extensively studied not only for its application as a photocatalyst but also as a device material for other purposes, such as light-emitting diodes, cathoderay tubes, thin film electroluminescence, reflector, dielectric filter, chemical/biological sensors, and window layers in photovoltaic cells [2]. In addition, zinc sulfide has the direct band gap of $3.68 \mathrm{eV}$ (zinc blend) and $3.80 \mathrm{eV}$ (wurtzite) at $300 \mathrm{~K} \mathrm{[3].} \mathrm{However,} \mathrm{its} \mathrm{wide} \mathrm{band} \mathrm{gap}$ restricts light absorption specifically to the wavelength of UV less than $340 \mathrm{~nm}$, where it can only take advantage of ultraviolet irradiation constituting only $4 \%$ of the incoming solar light [4]. Therefore, the development of visible-lightdriven photocatalysts by using less energy but more abundant visible light ( $\lambda \geq 420 \mathrm{~nm}$ ), which accounts for about $43 \%$ of the solar spectrum, has recently become a very important topic of research [5]. As visible-light-driven photocatalysts by doping nonmetal ions can provide more active sites and mechanisms on photocatalysts, those have been widely used to improve the visible-light-driven photocatalytic activity [6]. Therefore, in this paper, we attempted to prepare nitrogendoped $\mathrm{ZnS}$ nanostructures using thermal decomposition methods to degrade Orange II dye under visible light irradiation.

\section{Materials and Methods}

2.1. Preparation and Modification of Nitrogen-Doped ZnS Photocatalysts. Zinc chloride and potassium thiocyanate were used as the source of zinc and sulfur, respectively. $12.51 \mathrm{~g}$ of anhydrous $\mathrm{ZnCl}_{2}$ (Merck) was dissolved in $25 \mathrm{~mL}$ of water, and then $50 \mathrm{~mL}$ of ethanol (95\%) was added by 
constant stirring (solution A); $20.07 \mathrm{~g}$ of potassium thiocyanate (Merck) was separately dissolved in another $25 \mathrm{~mL}$ of water (solution B). Under magnetic stirring, solution B was then added drop by drop $(30 \mathrm{~min})$ into solution A. The clear solution was stirred for another $30 \mathrm{~min}$, and the solvents were evaporated on a hot plate until they became a semisolid, which was then transferred into a crucible for decomposition. Thermal decomposition of the semisolid was carried out under nitrogen conditions at $500^{\circ} \mathrm{C}$ for 2 hours. A series of nitrogen-doped $\mathrm{ZnS}$ photocatalysts prepared by controlling the inflow flow rate of nitrogen at $15,30,70$, and $140 \mathrm{~mL} / \mathrm{min}$ denoted as $15 \mathrm{~N} / \mathrm{ZnS}, 30 \mathrm{~N} / \mathrm{ZnS}$, $70 \mathrm{~N} / \mathrm{ZnS}$, and $140 \mathrm{~N} / \mathrm{ZnS}$, respectively, were prepared under nitrogen atmospheric conditions at $500^{\circ} \mathrm{C}$. After thermal decomposition at the desired temperature $\left(500^{\circ} \mathrm{C}\right)$, the samples were washed with plenty of water and methanol to eliminate the impurities and finally dried in an oven at $60^{\circ} \mathrm{C}$ overnight.

2.2. Characterizations and Instruments. The X-ray diffraction (XRD) patterns were recorded using RigakuUltima III diffractometer (Japan) with $\mathrm{Cu}-\mathrm{K} \alpha 1$ radiation, in the scan angle range from $10^{\circ}$ to $80^{\circ}$. The morphologies of the catalysts were examined by using JEOL, JSM-7401F field emission scanning electron microscope (FE-SEM). High-resolution transmission electron microscopic (HR-TEM) images were recorded using JEOL JEM-2010 model. Elemental analysis (EA) was conducted using a PerkinElmer CS02010 elemental analyzer. X-ray photoelectron spectroscopy (XPS) measurements were carried out using Physical Electronics PHI 5600 XPS instrument with monochromatic Al- $\mathrm{K} \alpha$ as $(1,486.6 \mathrm{eV})$ excitation source. The UV-visible diffuse reflectance spectra were recorded by a Shimadzu UV-2600 spectrophotometer equipped with an integrated sphere attachment using barium sulfate as a reference. The concentration of the Orange II dye was also determined by UV-2600 spectrophotometer equipped with a universal liquid cell attachment at the wavelength of $485 \mathrm{~nm}$.

2.3. Photocatalytic Activity. The photocatalytic experiments of the synthesized composite catalysts were performed in a $500 \mathrm{~mL}$ tubular quartz reactor. Catalyst dose and initial dye concentration were maintained at $0.5 \mathrm{~g} / \mathrm{L}$ and $40 \mathrm{mg} / \mathrm{L}$, respectively. The experiments were carried out at neutral $\mathrm{pH}$ under ambient condition. Prior to experiment, the catalyst and dye mixtures were stirred in the dark for $1 \mathrm{hr}$ to achieve adsorption equilibrium of Orange II dye on the surface of the catalysts. For light irradiation, the photocatalytic reactor was illuminated with a $350 \mathrm{~W}$ xenon light source, which has a cutoff filter at wavelength $400 \mathrm{~nm}$ allowing visible light to pass.

\section{Results and Discussion}

3.1. Characterization of Nitrogen-Doped ZnS Photocatalysts. The crystallinity and crystal phase of pure $\mathrm{ZnS}$ and nitrogendoped ZnS photocatalysts were characterized by XRD as shown in Figure 1. The major diffraction peaks of the $\mathrm{ZnS}$

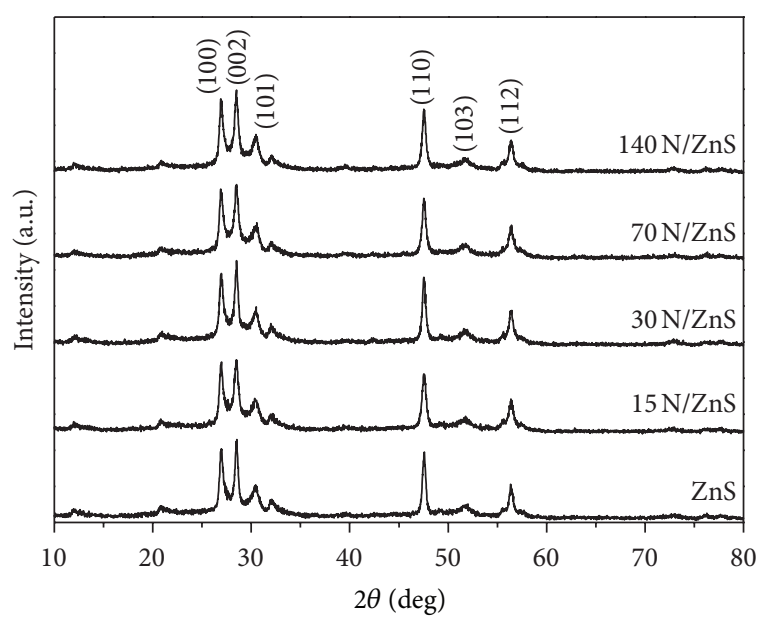

FIGURE 1: XRD patterns of nitrogen-doped and bare ZnS.

(JCPDS card number 36-1450, the lattice parameters of $a=$ $3.820 \AA$ and $c=6.257 \AA$ ) with (100), (002), (101), (110), (103), and (112) planes were apparent for hexagonal wurtzite crystal structure. The (002) peak intensity is stronger than the (100) peak when the nitrogen-doped $\mathrm{ZnS}$ composite catalysts were prepared under different conditions. This is due to the change in the stacking sequence of the close packed planes of the $\mathrm{ZnS}$ crystal [7]. This observation is supported by the TEM results, and it indicates that nanosheets preferential growth occurs along the $c$-axis. The remaining peaks are generally broad and probably indicate relatively small dimensions of the materials [8]. The (100), (002), and (101) peaks strongly overlap, implying the formation of well-crystallized $\mathrm{ZnS}$. At the same time, the atmospheric conditions have not influenced the crystal structure of $\mathrm{ZnS}$ [7].

HR-TEM images (Figure 2(a)) of the as-synthesized catalysts can further confirm the flowery structure of the microspheres. The clear lattice fringes (Figure 2(b)) also indicate the polycrystalline nature of the petals. The interplanar spacing is $0.31 \mathrm{~nm}$, which corresponds to the $(002)$ plane of wurtzite $\mathrm{ZnS}$. The corresponding selected area electron diffraction (SAED) patterns (Figure 2(c)) with a regular and clear ring diffraction spot array reveal that each petal is polycrystalline. Moreover, the major diffraction ring matches (100), (002), (101), (110), and (112) planes of ZnS phase.

To better understand chemical states of the elements within the catalysts, XPS analyses were performed in this study. The typical XPS results are shown in Figure 3. The peaks of $S$ and $\mathrm{Zn}$ can be clearly seen in the survey spectra of all catalysts used (Figures 3(b) and 3(c)). The binding energies of $S 2 p_{3 / 2}$ and $S 2 p_{1 / 2}$ at $161.1 \mathrm{eV}$ and $160.2 \mathrm{eV}$ (Figure 3(b)) are consistent with the binding energy values in the literature [9]. Moreover, the binding energy of $\mathrm{Zn} 2 \mathrm{p}_{3 / 2}$ and $\mathrm{Zn} 2 \mathrm{p}_{1 / 2}$ is $1020.3 \mathrm{eV}$ and $1043.3 \mathrm{eV}$ (Figure 3(c)), belonging to the $\mathrm{Zn}^{2+}$ oxidation state in $\mathrm{ZnS}$ [9]. As for $\mathrm{N}$, the binding energy of N1s at $395.9 \mathrm{eV}$ belongs to atomic $\beta-\mathrm{N}(396 \mathrm{eV})$ [10]. According to the references, N1s peak at $396 \mathrm{eV}$ is attributed 


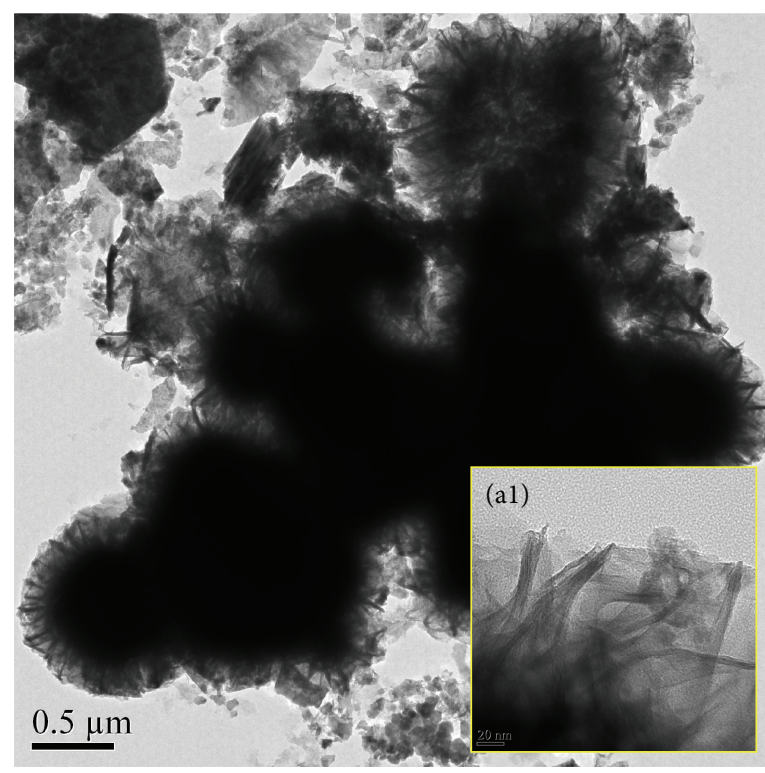

(a)

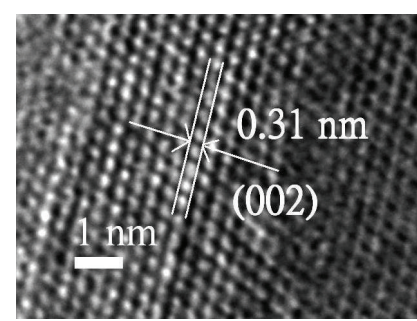

(b)

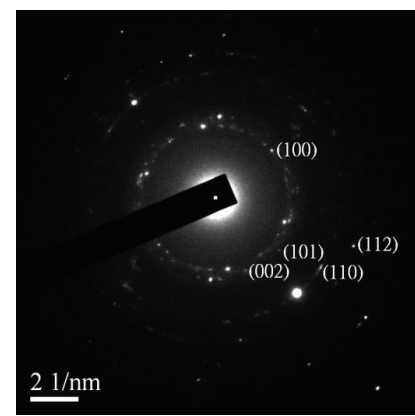

(c)

Figure 2: (a) HR-TEM images, (b) lattice fringes, and (c) the corresponding SAED pattern of 15N/ZnS.

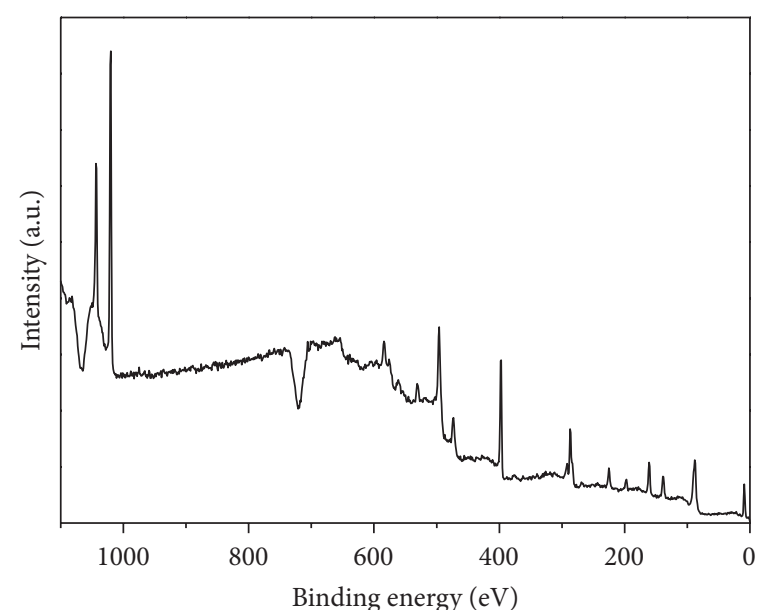

(a)

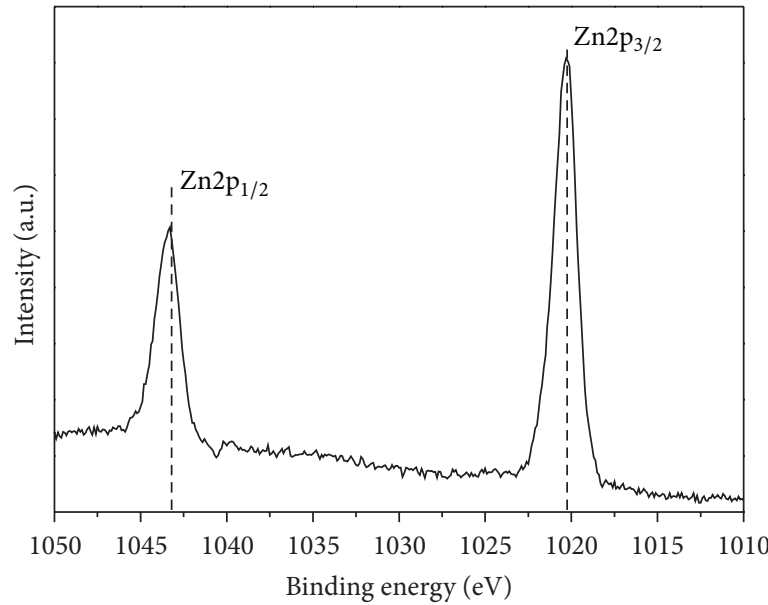

(c)

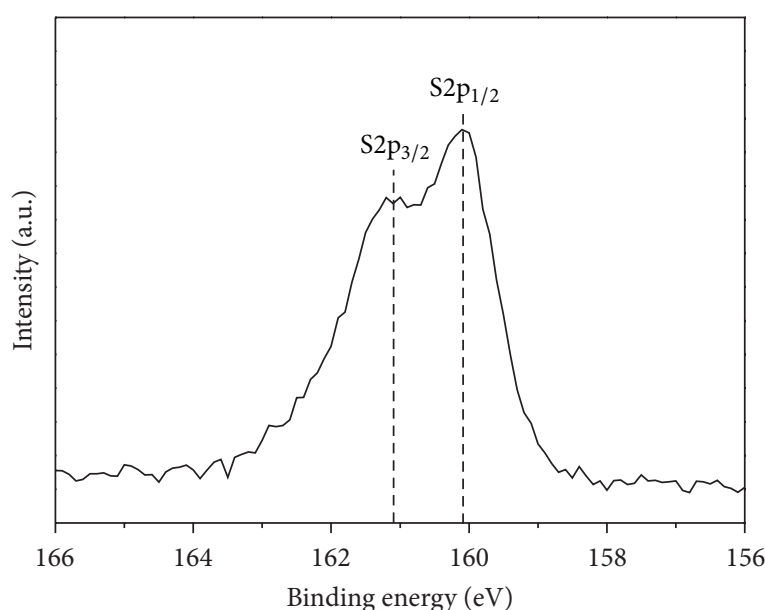

(b)

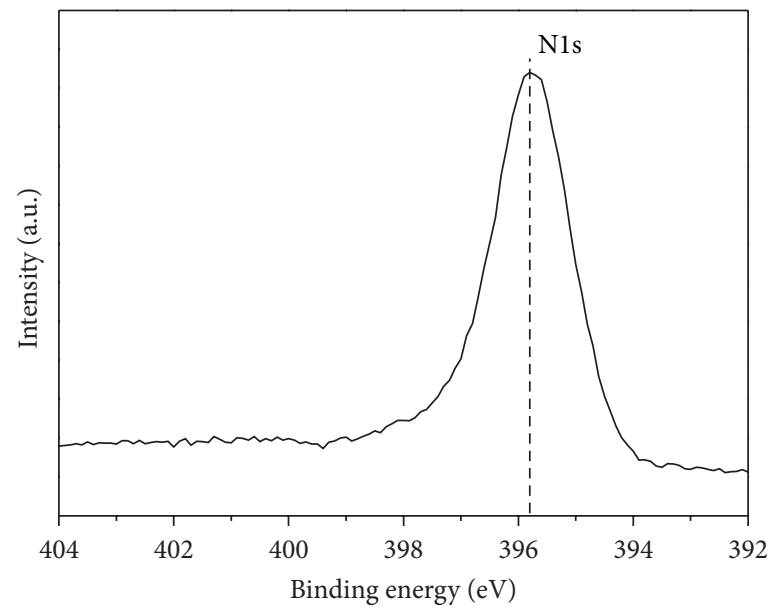

(d)

Figure 3: The survey XPS spectra of (a) 15N/ZnS photocatalysts and the high-resolution XPS spectra of (b) S2p, (c) Zn2p, and (d) N1s of $15 \mathrm{~N} / \mathrm{ZnS}$ photocatalysts. 


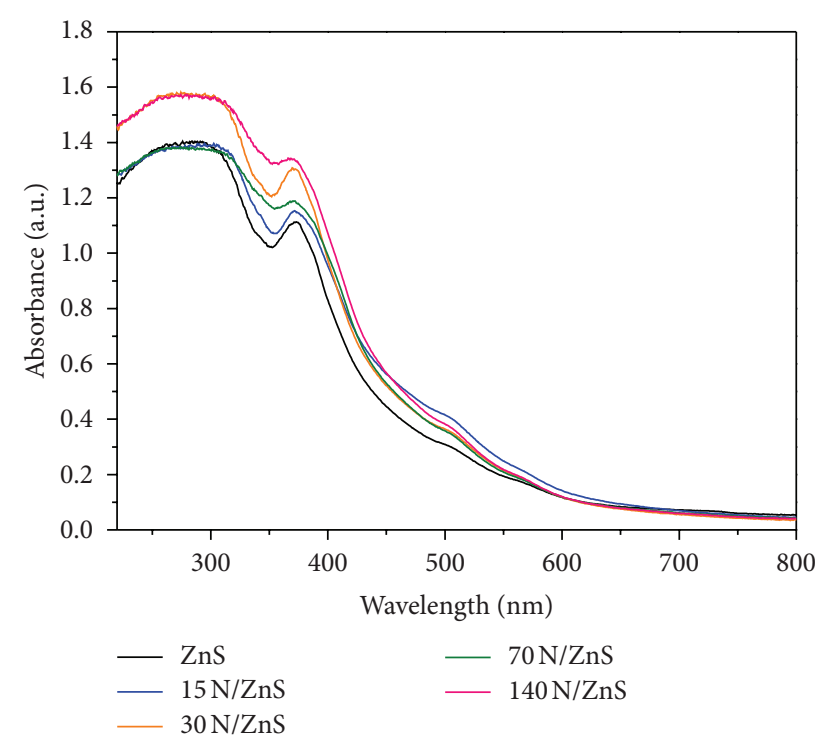

FIGURE 4: UV-Vis absorption spectra of as-synthesized photocatalysts.

to a characteristic peak of substitutional $N$, resulting from the nitrogen substitution of sulfur in the $\mathrm{ZnS}$ lattice [10-12]. In addition, the substitutional doping of $\mathrm{N}$ is thought to be the most pronounced because its $p$ states contribute to the band gap narrowing by mixing with $S 2 p$ states [10]. From the UVVis absorption spectra results as shown in Figure 4, the band gap of bare $\mathrm{ZnS}$ was calculated as $2.95 \mathrm{eV}$. The band gap of nitrogen-doped $\mathrm{ZnS}$ composite catalysts is between 2.58 and $2.74 \mathrm{eV}$. Therefore, the redshift in UV-Vis absorption spectra is enhanced by the nitrogen-doped $\mathrm{ZnS}$ composite catalysts, which implies the potential absorption to effectively harvest visible light.

The morphology of nitrogen-doped $\mathrm{ZnS}$ composite catalysts was characterized by FE-SEM as shown in Figure 5. The zinc isothiocyanate complex thermal decompositions have been carried out at $500^{\circ} \mathrm{C}$ under nitrogen conditions. The $\mathrm{ZnS}$ photocatalysts consist of irregular spheres with an average diameter of $1 \mu \mathrm{m}$ and seem to facilitate microsphere aggregation. The images in Figures 5(a)-5(e) show that the nitrogen-doped ZnS Camellia Brushfield Yellowlike structure comprises numerous $\mathrm{ZnS}$ particles (petals) and the nitrogen-doped $\mathrm{ZnS}$ crystallites are self-organized into spherical assemblies, or a Camellia Brushfield Yellow-like morphology, with a puffy appearance. The nitrogen-doped $\mathrm{ZnS}$ products are all in this morphology with diameters ranging from 300 to $700 \mathrm{~nm}$. The gap between particles (petals) was observed in the average range of $100 \mathrm{~nm}$. The nitrogen-doped $\mathrm{ZnS}$ flower is quite open and puffy with ZnS particles (petals) that have good crystallinity [13]. When the nitrogen flowrate was increased from 15 to $140 \mathrm{~mL} / \mathrm{min}$, the morphology of the nitrogen-doped $\mathrm{ZnS}$ nanoparticles became more rough as seen in Figures 5(a)-5(e). Figure 5(f) clearly indicates that the flowery structures, from which one can see that dozens of 2D sheets are intercrossed with each other, have been formed throughout their self-assembly mechanisms.
Furthermore, based on the experimental results, we considered that the formation mechanism of the as-synthesized product of nitrogen-doped ZnS Camellia Brushfield Yellowlike structure could be explained by a synergic effect of Ostwald ripening and the self-assembled mechanism as proposed in Figure 6. In the first stage, tiny crystalline nuclei are generated in the mixed solution and grow into nanoparticles. These nanoparticles are built and aggregated into spheres to minimize their surface area through the process known as Ostwald ripening [14, 15]. In the second stage, the thiocyanate ion $\left(\mathrm{SCN}^{-}\right)$coordinates with a variety of metal ions. It can form isothiocyanate (M-NCS) complexes that are further decomposed into metal sulfides with high purity [9]. The thermal decomposition of the $\mathrm{Zn}(\mathrm{SCN})_{2}$ complex at $500^{\circ} \mathrm{C}$ results in weakening of the coordination of $\mathrm{Zn}-\mathrm{NCS}$ complex, and $\mathrm{SO}_{2}, \mathrm{CO}_{2}$, and $\mathrm{N}_{2}$ will be released gradually [15]. Then the crystallized particles grow along the $2 \mathrm{D}$ direction, resulting in the formation of nanosheets as shown in Figure 2(a1). As the mass diffusion and Ostwald ripening process proceed, the nanosheets can grow until all the nanoparticles are consumed, accompanied by their self-organization into the Camellia Brushfield Yellow-like structure. In addition, the increase of inflow flowrate of nitrogen until $140 \mathrm{~mL} / \mathrm{min}$ has resulted in the increase of $\mathrm{N}$ atoms in the $\mathrm{ZnS}$ structure. According to the energy dispersive system (EDS) results on the catalyst surface, the nitrogen atom concentration of $15 \mathrm{~N} / \mathrm{ZnS}, 30 \mathrm{~N} / \mathrm{ZnS}, 70 \mathrm{~N} / \mathrm{ZnS}$, and $140 \mathrm{~N} / \mathrm{ZnS}$ is $5.31 \%$, $7.88 \%, 12.57 \%$, and $17.98 \%$, respectively. To quantify the impurities of carbon in the $\mathrm{ZnS}$ structure, elemental analysis (EA) was used and the carbon impurities were found to be $7.0 \pm 0.14 \%(\mathrm{w} / \mathrm{w})$ in all as-synthesized $\mathrm{ZnS}$ powders, which implies that the thermal decomposition at $500^{\circ} \mathrm{C}$ cannot remove the carbon impurities perfectly in the $\mathrm{ZnS}$ structure, but the residual carbon concentration is relatively low. The different morphology of $140 \mathrm{~N} / \mathrm{ZnS}$ can be ascribed to the production of more decomposed products, including $\mathrm{SO}_{2}, \mathrm{CO}_{2}, \mathrm{NO}_{2}$, and $\mathrm{N}_{2}$, to go off readily from the catalyst surface during the decomposition process [16].

3.2. Photocatalytic Activity. The photocatalytic activities of the prepared nitrogen-doped $\mathrm{ZnS}$ nanoparticles were evaluated for the degradation of Orange II dye under visible light irradiation. Figure 7(a) shows the removal percentage of Orange II dye as a function of reaction time using bare and nitrogen-doped $\mathrm{ZnS}$ catalysts. The Orange II dye concentration was removed around $5.0 \%$ and $5.1 \%$ after 300 minutes of visible-light irradiation in the presence of commercial $\mathrm{ZnS}$ and as-synthesized bare $\mathrm{ZnS}$, respectively. The optimal degradation ratio of Orange II dye using $15 \mathrm{~N} / \mathrm{ZnS}$ photocatalyst was found to be $75.7 \%$ after 300 -minute irradiation. However, the increase of nitrogen-doped amount on the $\mathrm{ZnS}$ photocatalyst would result in the decrease of dye removal. The efficient removal of Orange II dye using visible-light photocatalysis by nitrogen-doped $\mathrm{ZnS}$ can be attributed to the response from occupied N2p localized states slightly above the valence band edge [11]. The decrease in photocatalytic activity observed in the higher 


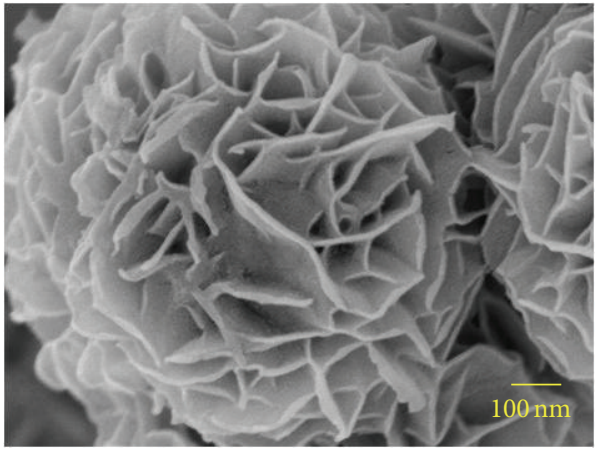

(a)

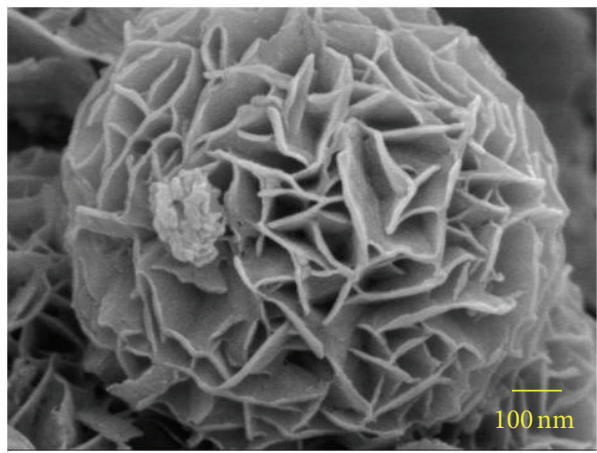

(c)

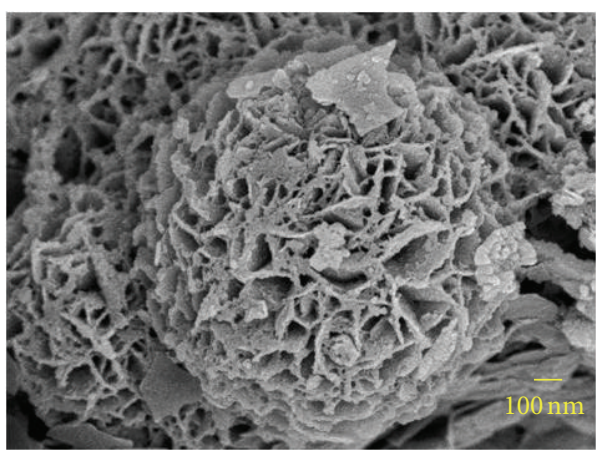

(e)

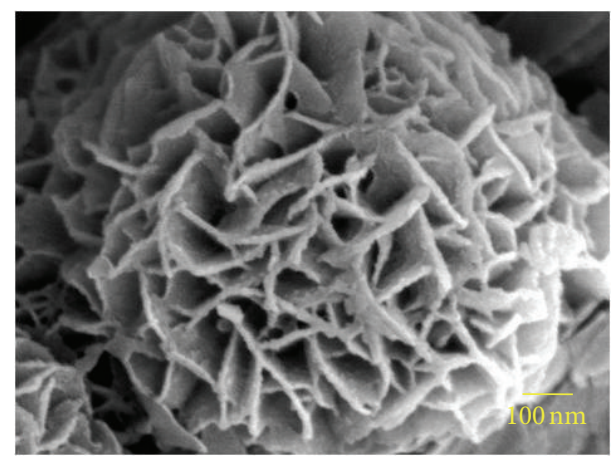

(b)

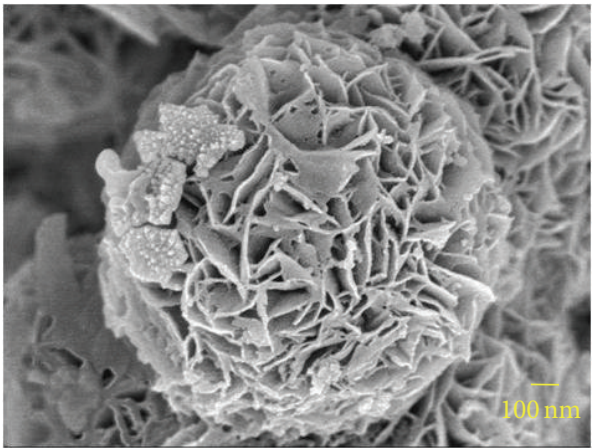

(d)

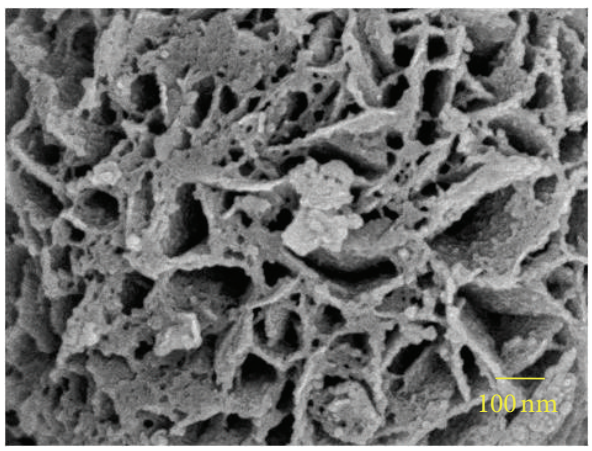

(f)

Figure 5: FE-SEM images of (a) ZnS, (b) 15N/ZnS, (c) 30N/ZnS, (d) 70N/ZnS, and (e) 140N/ZnS photocatalysts.

nitrogen-doping $\mathrm{ZnS}$, such as $140 \mathrm{~N} / \mathrm{ZnS}$ powder, may be attributed to a change in the crystal structure of the sample caused by the high doping of $\mathrm{N}$ in the crystal, though we did not find a noticeable change in XRD. As a result, such a surface roughness can function as traps for photogenerated electrons and holes, reducing the efficiency of photocatalysis [17].

Furthermore, the decomposition process is modeled as a pseudo-first-order reaction with the kinetics expressed by the equation $\ln \left(C_{0} / C_{t}\right)=k t$, where $C_{0}$ represents the initial concentration, $C_{t}$ denotes the concentration at a given reaction time $(t)$, and $k$ is the reaction rate constant. From the linear extrapolations as shown in Figure 5(b), the reaction rate constants were calculated as $4.63 \times 10^{-3} \mathrm{~min}^{-1}, 3.04 \times 10^{-3} \mathrm{~min}^{-1}, 1.41 \times 10^{-3} \mathrm{~min}^{-1}$,
$1.09 \times 10^{-3} \mathrm{~min}^{-1}$, and $1.80 \times 10^{-4} \mathrm{~min}^{-1}$, respectively, using $15 \mathrm{~N} / \mathrm{ZnS}, 30 \mathrm{~N} / \mathrm{ZnS}, 70 \mathrm{~N} / \mathrm{ZnS}, 140 \mathrm{~N} / \mathrm{ZnS}$, and bare $\mathrm{ZnS}$ photocatalysts. The results indicate that the $\mathrm{N}$-doping $\mathrm{ZnS}$ shows better photocatalytic activity than bare $\mathrm{ZnS}$ under visible light irradiation due to the shorter band gap. However, the increase of $\mathrm{N}$-doping will negate the efficiency by its surface roughness.

\section{Conclusions}

In summary, we have successfully synthesized nitrogendoped $\mathrm{ZnS}$ composite catalysts with the Camellia Brushfield Yellow-like structure. The obtained surface and optical characteristics demonstrate that the nitrogen-doped $\mathrm{ZnS}$ can act as a good visible-light-driven photocatalyst. Their visible 


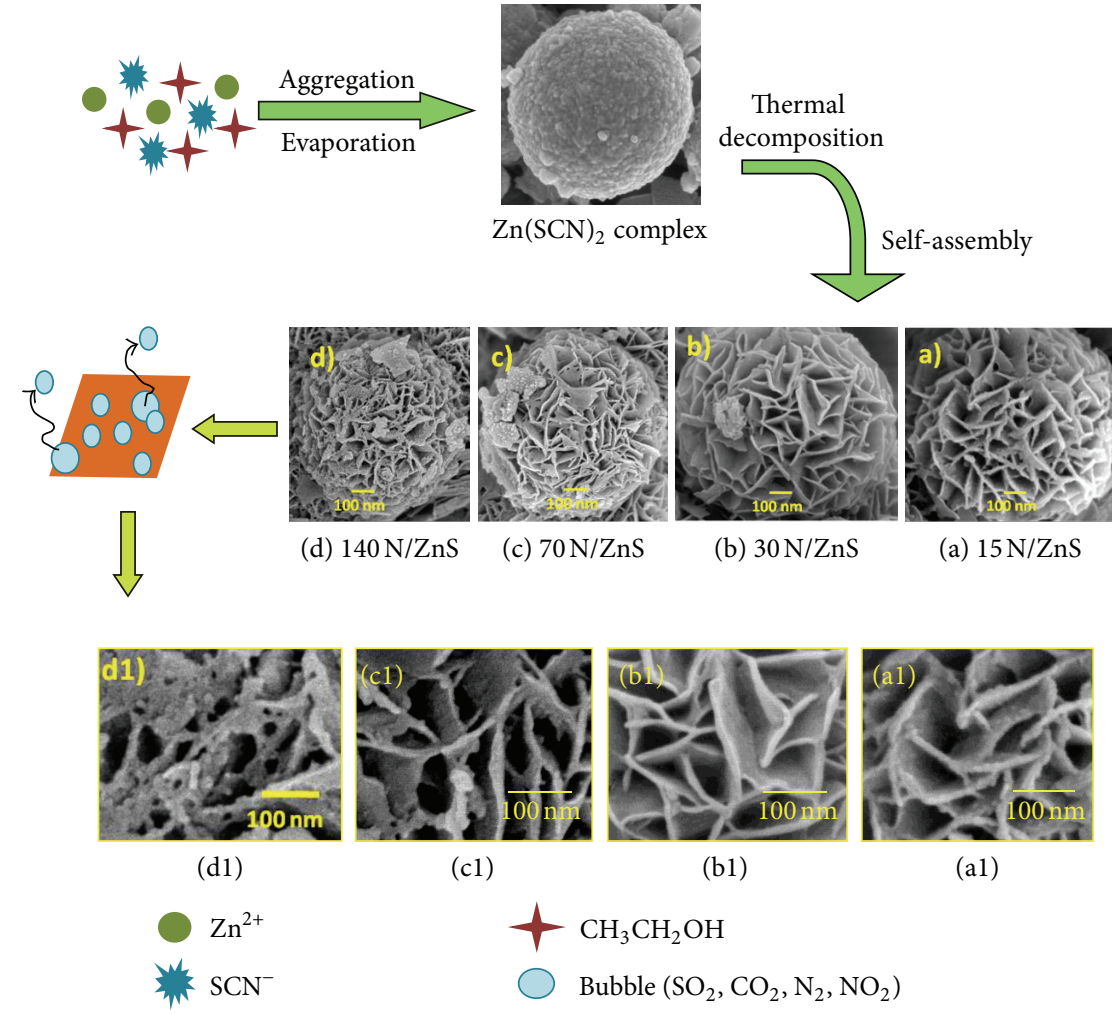

FIGURE 6: Schematic illustration of possible growth mechanism of nitrogen-doped ZnS Camellia Brushfield Yellow-like structure.

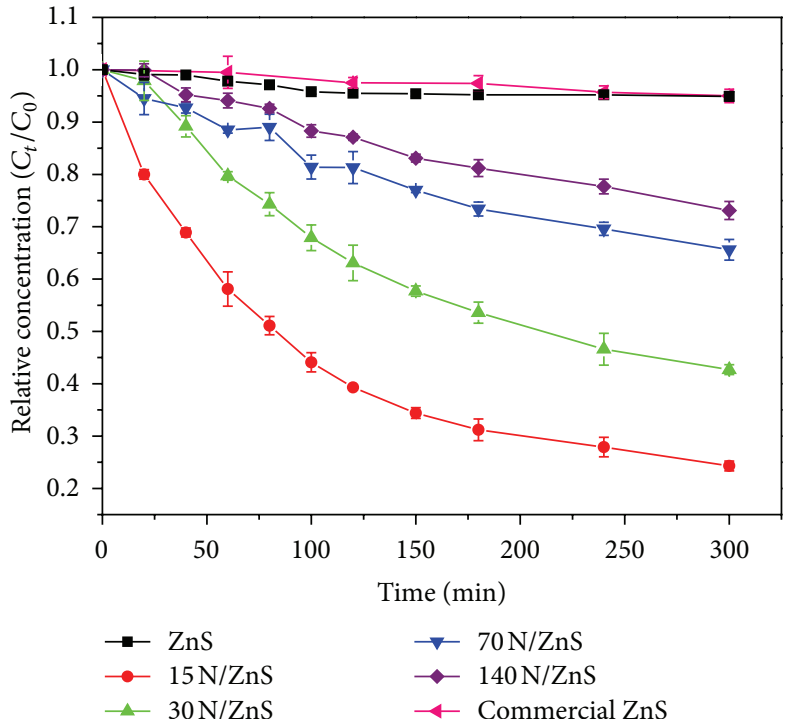

(a)

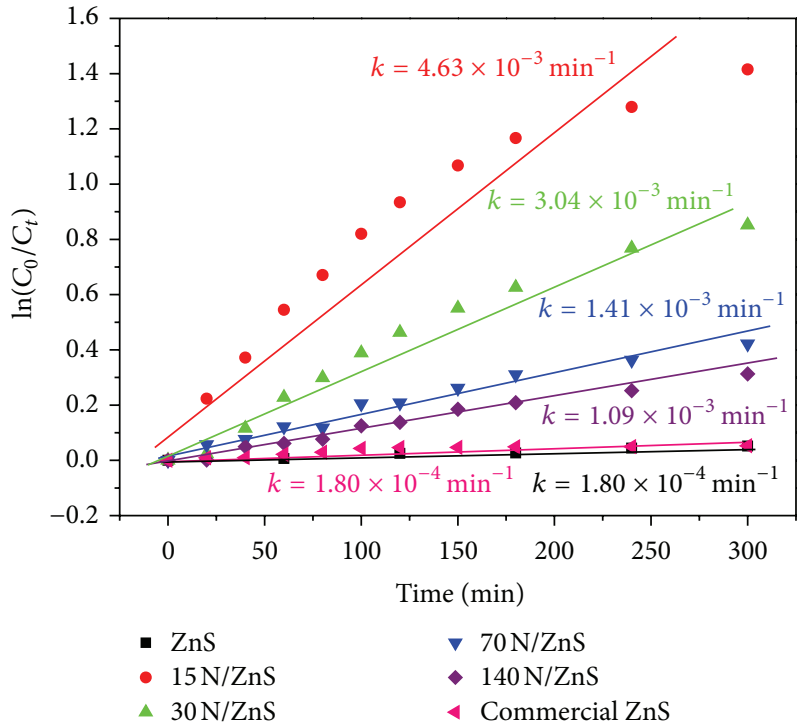

(b)

FIGURE 7: (a) Photocatalytic degradation of Orange II dye in the presence of bare and different nitrogen-doped ZnS photocatalysts; (b) plot of $\ln \left(C_{0} / C_{t}\right)$ versus time for photocatalytic degradation of Orange II dye in presence of bare and different nitrogen-doped ZnS photocatalysts.

light assisted photocatalytic ability has been shown by the degradation of azo dye Orange II. The effect of nitrogendoped amount on the photocatalytic on the removal of Orange II dye suggests that $15 \mathrm{~N} / \mathrm{ZnS}$ is the optimum loading for better photocatalytic ability.

\section{Acknowledgments}

The authors wish to acknowledge the financial support by the National Science Council in Taiwan with the Grant no. NSC-101-2221-E-035-031-MY3. The support in providing the fabrication and measurement facilities from the Precision 
Instrument Support Center of Feng Chia University is also acknowledged.

\section{References}

[1] D. I. Kondarides, A. Patsoura, and X. E. Verykios, "Anaerobic photocatalytic oxidation of carbohydrates in aqueous $\mathrm{pt} / \mathrm{TiO}_{2}$ suspensions with simultaneous production of hydrogen," Journal of Advanced Oxidation Technologies, vol. 13, no. 1, pp. 116123, 2010.

[2] S. K. Maji, A. K. Dutta, D. N. Srivastava, P. Paul, A. Mondal, and B. Adhikary, "Effective photocatalytic degradation of organic pollutant by $\mathrm{ZnS}$ nanocrystals synthesized via thermal decomposition of single-source precursor," Polyhedron, vol. 30, no. 15, pp. 2493-2498, 2011.

[3] M. Navaneethan, J. Archana, K. D. Nisha et al., "Synthesis of wurtzite $\mathrm{ZnS}$ nanorods by microwave assisted chemical route," Materials Letters, vol. 66, no. 1, pp. 276-279, 2012.

[4] J. Zhu and M. Zäch, "Nanostructured materials for photocatalytic hydrogen production," Current Opinion in Colloid and Interface Science, vol. 14, no. 4, pp. 260-269, 2009.

[5] N. Bao, L. Shen, T. Takata, and K. Domen, "Self-templated synthesis of nanoporous CdS nanostructures for highly efficient photocatalytic hydrogen production under visible light," Chemistry of Materials, vol. 20, no. 1, pp. 110-117, 2008.

[6] X. Chen, S. Shen, L. Guo, and S. S. Mao, "Semiconductorbased photocatalytic hydrogen generation," Chemical Reviews, vol. 110, no. 11, pp. 6503-6570, 2010.

[7] M. Muruganandham and Y. Kusumoto, "Synthesis of N, C codoped hierarchical porous microsphere $\mathrm{ZnS}$ as a visible lightresponsive photocatalyst," The Journal of Physical Chemistry C, vol. 113, no. 36, pp. 16144-16150, 2009.

[8] S. K. Maji, A. K. Dutta, D. N. Srivastava, P. Paul, A. Mondal, and B. Adhikary, "Effective photocatalytic degradation of organic pollutant by $\mathrm{ZnS}$ nanocrystals synthesized via thermal decomposition of single-source precursor," Polyhedron, vol. 30, no. 15, pp. 2493-2498, 2011.

[9] Y. Liu, J. Hu, C. Ngo et al., "Gram-scale wet chemical synthesis of wurtzite-8H nanoporous $\mathrm{ZnS}$ spheres with high photocatalytic activity," Applied Catalysis B: Environment, vol. 106, no. 1-2, pp. 212-219, 2011.

[10] R. Asahi, T. Morikawa, T. Ohwaki, K. Aoki, and Y. Taga, "Visible-light photocatalysis in nitrogen-doped titanium oxides," Science, vol. 293, no. 5528, pp. 269-271, 2001.

[11] F. Peng, L. Cai, H. Yu, H. Wang, and J. Yang, "Synthesis and characterization of substitutional and interstitial nitrogendoped titanium dioxides with visible light photocatalytic activity," Journal of Solid State Chemistry, vol. 181, no. 1, pp. 130-136, 2008.

[12] H. Gao, J. Zhou, D. Dai, and Y. Qu, "Photocatalytic activity and electronic structure analysis of $\mathrm{N}$-doped anatase $\mathrm{TiO}_{2}$ : a combined experimental and theoretical study," Chemical Engineering and Technology, vol. 32, no. 6, pp. 867-872, 2009.

[13] B. B. Kale, J.-O. Baeg, S. M. Lee, H. Chang, S.-J. Moon, and C. W. Lee, "CdIn $\mathrm{S}_{4}$ nanotubes and "marigold" nanostructures: a visible-light photocatalyst," Advanced Functional Materials, vol. 16, no. 10, pp. 1349-1354, 2006.

[14] L. Zhou, W. Wang, H. Xu, S. Sun, and M. Shang, " $\mathrm{Bi}_{2} \mathrm{O}_{3}$ hierarchical nanostructures: controllable synthesis, growth mechanism, and their application in photocatalysis," Chemistry-A European Journal, vol. 15, no. 7, pp. 1776-1782, 2009.
[15] M. Muruganandham, Y. Kusumoto, C. Okamoto, A. Muruganandham, M. Abdulla-Al-Mamun, and B. Ahmmad, "Mineralizer-assisted shape-controlled synthesis, characterization, and photocatalytic evaluation of CdS microcrystals," The Journal of Physical Chemistry C, vol. 113, no. 45, pp. 19506-19517, 2009.

[16] M. Muruganandham, A. Ramakrishnan, Y. Kusumoto, and M. Sillanpää, "Are dopant-stabilized visible light-responsive photocatalysts efficient and stable?" Physical Chemistry Chemical Physics, vol. 12, no. 44, pp. 14677-14681, 2010.

[17] K. Maeda and K. Domen, "Solid solution of GaN and $\mathrm{ZnO}$ as a stable photocatalyst for overall water splitting under visible light," Chemistry of Materials, vol. 22, no. 3, pp. 612-623, 2010. 

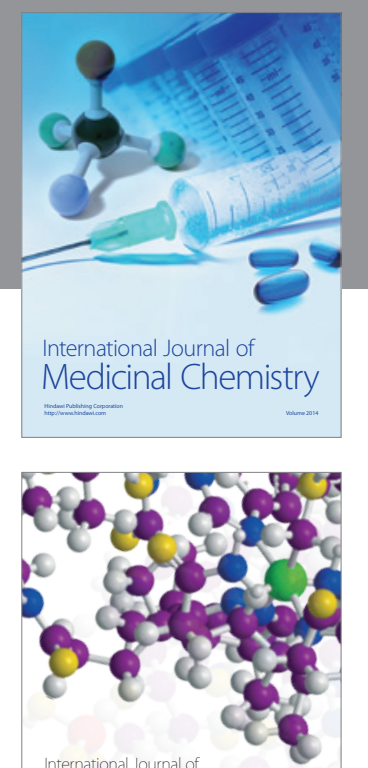

\section{Carbohydrate} Chemistry

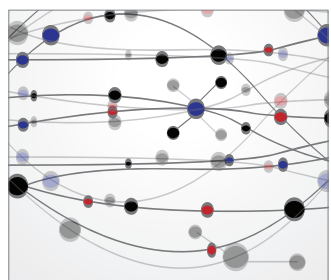

The Scientific World Journal
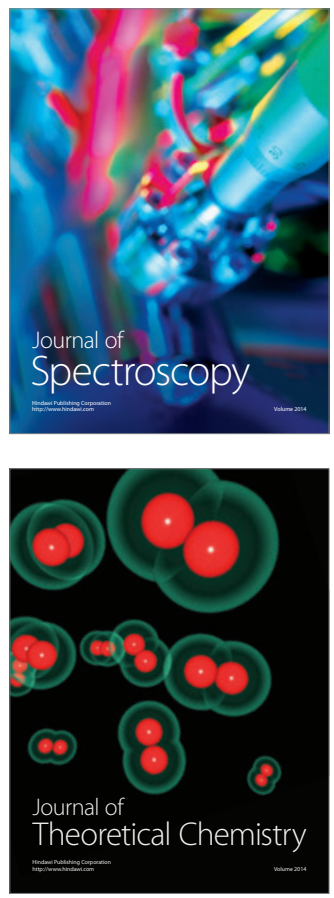
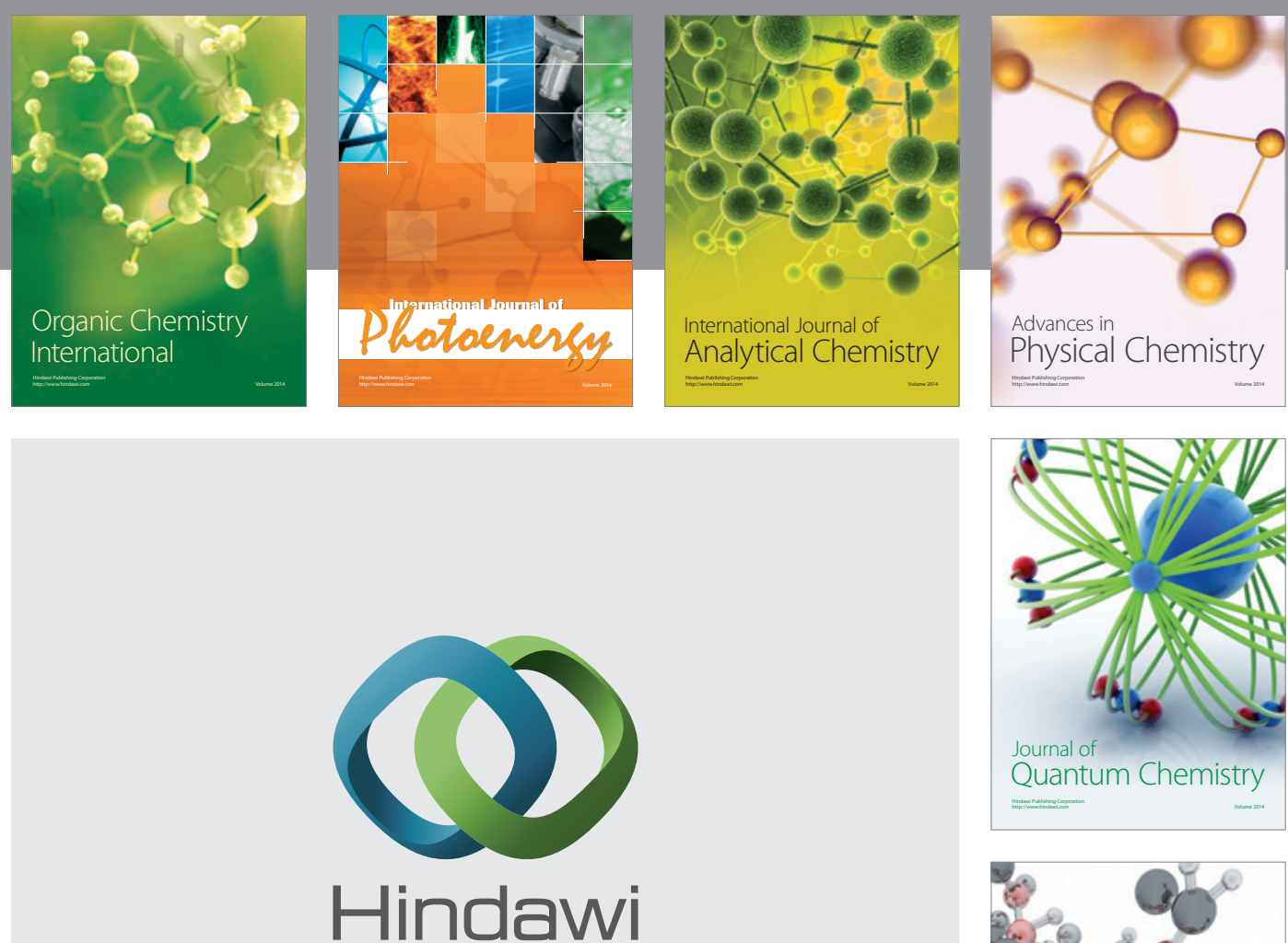

Submit your manuscripts at

http://www.hindawi.com

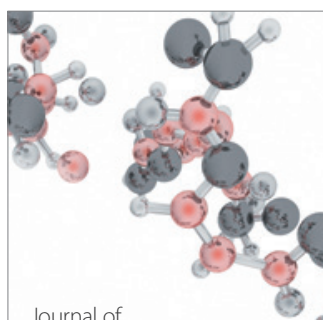

Analytical Methods

in Chemistry

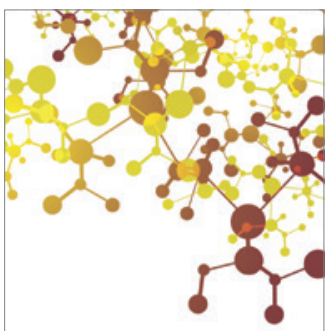

Journal of

Applied Chemistry

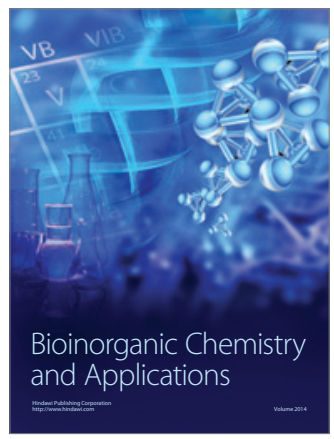

Inorganic Chemistry
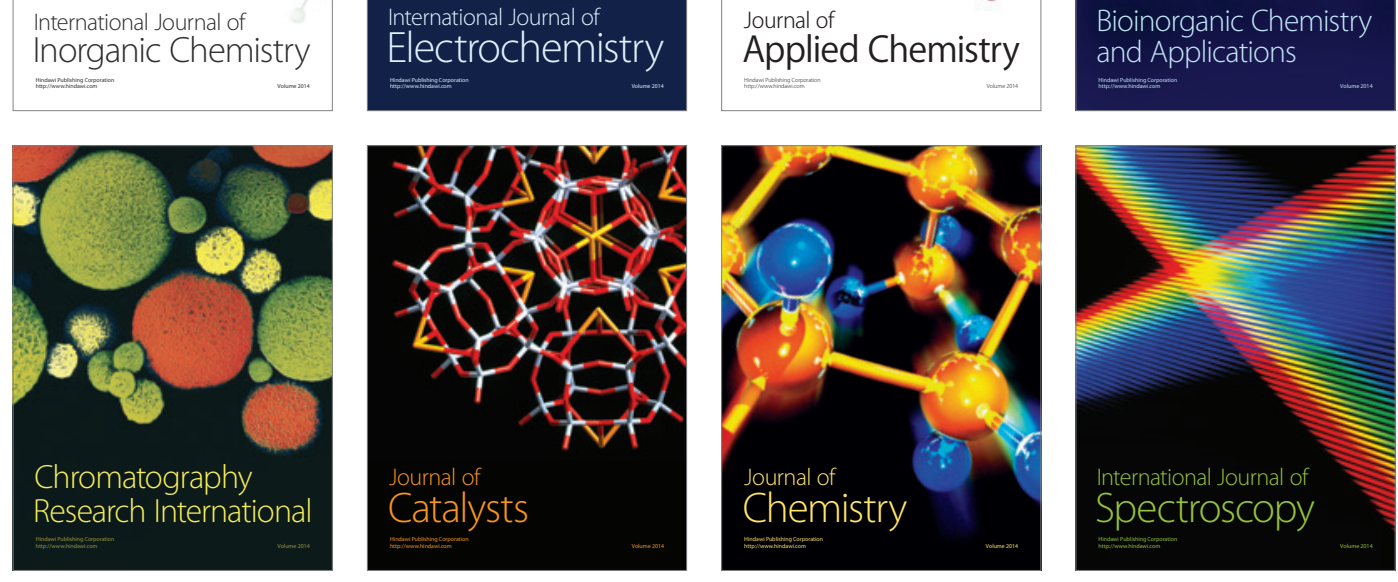